\title{
Erratum to: Quality and uptake of antenatal and postnatal care in Haiti
}

Kelsey R. Mirkovic ${ }^{*}$, Eva Lathrop², Erin N. Hulland ${ }^{2}$, Reginald Jean-Louis ${ }^{3}$, Daniel Lauture ${ }^{3,4}$, Ghislaine Desinor D'Alexis ${ }^{4}$, Endang Handzel ${ }^{2}$ and Reynold Grand-Pierre ${ }^{4}$

\section{Erratum}

In the original publication of this article [1], the author Endang Hanzel was written incorrectly. The correct spelling should have been Endang Handzel. The original article has now been updated to reflect this change.

\section{Author details}

${ }^{1}$ Epidemic Intelligence Service, Centers for Disease Control and Prevention, Atlanta, GA, USA. ²Division of Global Health Protection, Centers for Disease Control and Prevention, Atlanta, GA, USA. ${ }^{3}$ Division of Global Health

Protection, Centers for Disease Control and Prevention, Port-au-Prince, Haiti.

${ }^{4}$ Haiti Ministry of Public Health and Population, Port-au-Prince, Haiti.

Received: 16 February 2017 Accepted: 24 February 2017

Published online: 14 March 2017

\section{Reference}

1. Mirkovic K, et al. Mitochondrial Quality and uptake of antenatal and postnatal care in Haiti. BMC Pregnancy Childbirth. 2017;17:52. doi:10.1186/ s12884-016-1202-7.

\footnotetext{
*Correspondence: kmirkovic@cdc.gov

${ }^{1}$ Epidemic Intelligence Service, Centers for Disease Control and Prevention, Atlanta, GA, USA
} 